\title{
Primary Malignant Tumours of the Trigeminal Nerve
}

\author{
F.B. Maroun, M. Sadler, G.P. Murray, M. Mangan, \\ G. Mathieson, J.C. Jacob and A. Kwan
} ABSTRACT: We report a case of primary malignant schwannoma of the trigeminal nerve, and review the 5
previously reported cases. Clinical presentation, along with radiological and pathological features are discussed.

RÉSUMÉ: Des tumeurs primaires malins du nerf trijumeau Un sixième cas de neurinome primaire malin du trijumeau est présenté avec une revue de la littérature. La présentation clinique et les manifestations radiologiques et pathologiques sont discutées.

Can. J. Neurol. Sci. 1986; 13:146-148

Schwannomas of the trigeminal nerve are rare; 120 cases had been described up to $1972 .^{1.2}$ Malignant schwannoma is very rare, with only five cases having been reported. ${ }^{3.5}$ These malignant tumours, which are believed to arise from schwannoma cells, ${ }^{6.7}$ have been termed malignant schwannoma, neurogenic sarcoma, malignant neurilemmoma, neurofibrosarcoma. ${ }^{8}$ As experience with these tumours is limited, their management is a subject of controversy.

In this paper, we present a new case of malignant schwannoma of the trigeminal nerve and review the five previously reported cases.

\section{Case Report}

A 49 year old woman was admitted in April 1984 with a one month history of left sided facial and periorbital pain, and a two week history of diplopia. The only abnormality on examination was left lateral rectus paresis. Investigations which included an edrophonium test to rule out myasthenia gravis, and a CT head scan, were negative. It was postulated that the sixth nerve palsy may have resulted from a small hemorrhage into the abducens nerve as a complication of long term anticoagulant therapy which she had been taking for lower limb thrombophlebitis. Anticoagulant therapy was discontinued.

At follow-up in August 1984 she reported that the facial pain had increased in severity and there was no improvement in diplopia. There was loss of sensation in the territory of the first and second divisions of the left trigeminal nerve, and absent left corneal reflex, decreased taste in the anterior two-thirds of the left side of the tongue, left masseter weakness, and a persistent left sixth nerve palsy.
A CT head scan (Figure 1), performed in the coronal plane, showed destructive bone change involving the superior aspect of the clivus on the left side, and the left side of the dorsum sella. A mass lesion demonstrated in this region extended into the sphenoid sinus on the left side, and had also breeched the posterior aspect of the floor of the sphenoid sinus to extend to the right of the sphenoid septum. There was lateral extension to involve the carotid canal, as well as involvement of the cavernous sinus (Figure 2).

At surgery, through a transnasal-transphenoidal approach, part of the tumour, which was in the posterior aspect of the sphenoid sinus, was removed. It was hard, avascular, and whitish. Detailed histologic examination using multiple stains including hematoxylin and eosin, PAS, PTAH, Masson's, Holmes and reticulin revealed a highly cellular spindle-celled tumour (Figure 3). The cells showed bipolar fibrillary components and were arranged in fascicles. Coursing through the tumour, were individual myelinated axons but no bundles of nerve fibres were evident. The lesion lacked Antoni type A and B areas and had widely separated axons running through it. It was felt that the tissue pattern was that of a neurofibromatous lesion and the cellular features were considered to be indicative of malignancy.

Post-operatively she received radiotherapy (total of 6000 rads) to the base of the skull and the left middle fossa. Though her facial and orbital pain abated. she developed a sixth nerve palsy on the right and wasting of the tongue on the left.

\section{Discussion}

Tumours of the trigeminal nerve usually present with pain or numbness in the face. As the tumour grows to involve the cavernous sinus (as occurred in our patient), extraocular mus-

From the Divisions of Neurosurgery and Neurology. Departments of Radiology and Pathology, Memorial University of Newfoundland, Health Sciences Centre, St. John's, Newfoundland

Received July 3, 1985. Accepted in final form January 22, 1986

Reprint requests to: Dr. F.B. Maroun, Wedgewood Medical Centre, 12 Gieneyre Street. St. John's. Nfld. AIA 2 M7 


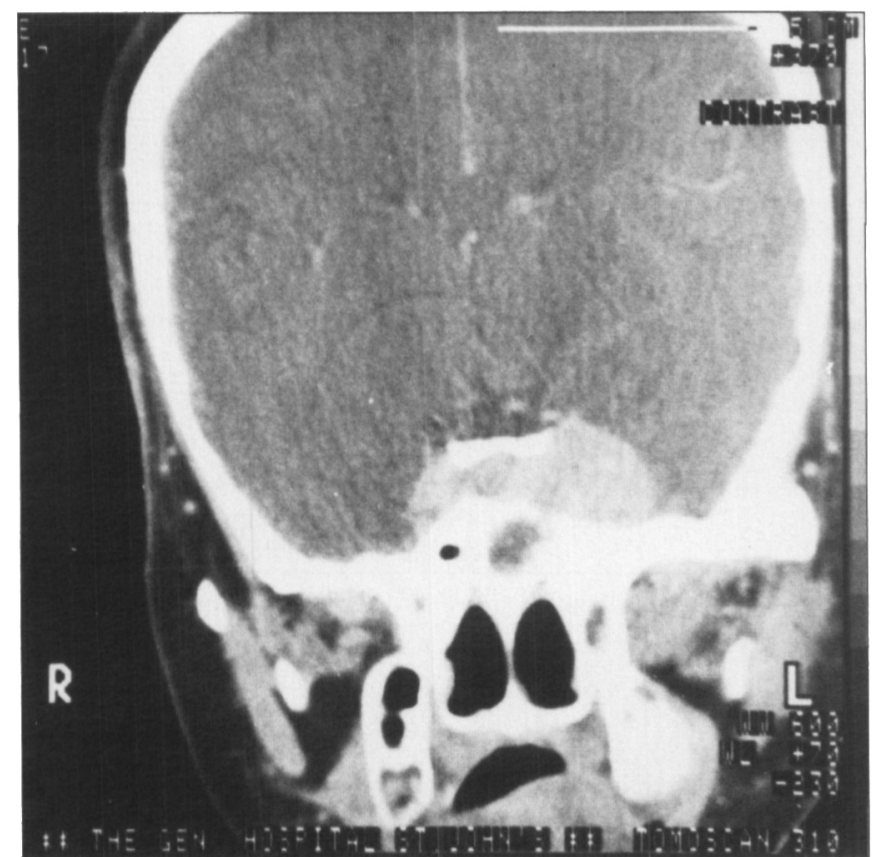

Figure l: Coronal CT scan with enhancement. Parasellar mass lesion extending into sphenoid sinus.

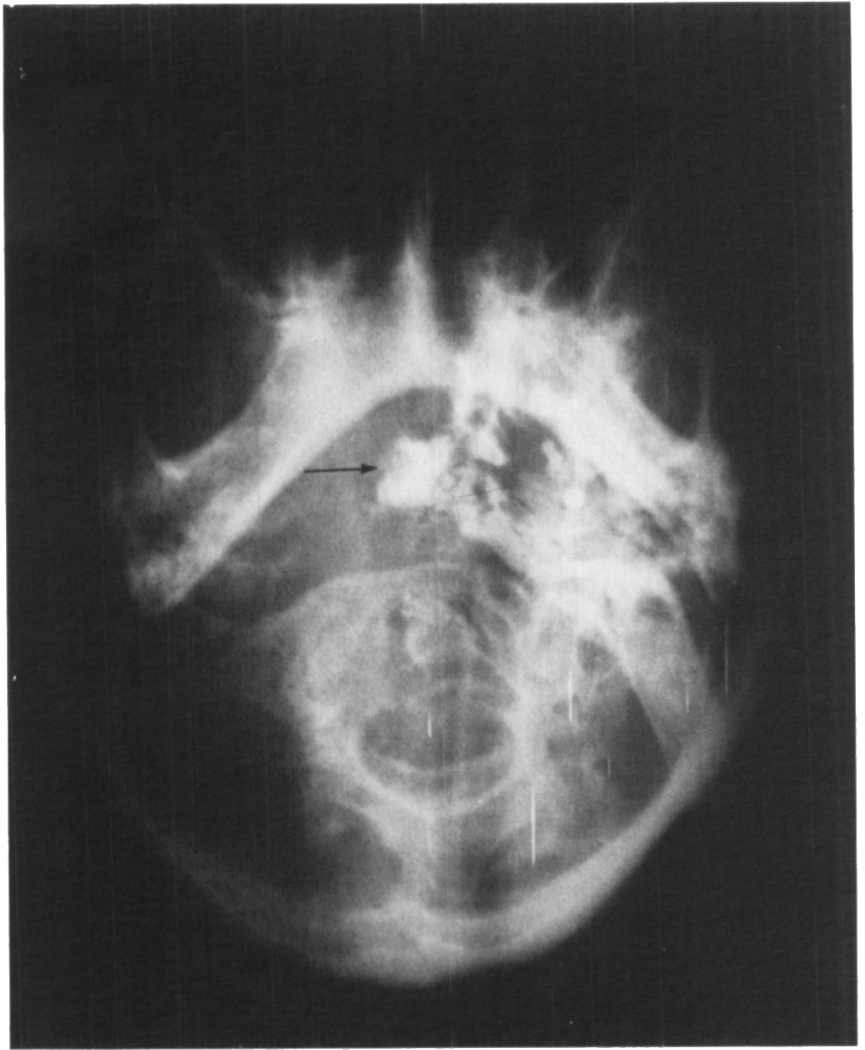

Figure 2: Right cavernous phlebogram (base view) showing amputation of basilar plexus on left with no filling of left cavernous sinus.

cle dysfunction may occur. As the tumour further erodes through the petrous ridge into the posterior fossa, involvement of any of the lower cranial nerves may occur, and clinical features may also include cerebellar and pyramidal tract signs.

The pathogenesis of malignant change in a benign schwannoma is unknown. However, there have been 21 cases reported of neurofibrosarcomas occurring in peripheral nerves after radiation exposure.$^{7.9 .10 .11}$ Our patient had not received any prior radiation therapy.

Both benign and malignant peripheral nerve sheath tumours have a common association with neurofibromatosis. ${ }^{8.12}$ Brasfield and Das Gupta ${ }^{12}$ estimated that more than fifty percent of people with Von Recklinghausen's disease over the age of 50 will develop malignant change in a neurofibroma. In the five previously reported cases of malignant trigeminal schwannomas there was no family history or clinical evidence of Von Recklinghausen disease. The same holds true for our patient.

Table 1 summarises the clinical features of the previous case reports.

The pathological findings of our case were consistent with other reported cases. Typically these tumours show a mixture of spindle and polyhedral cells with hyperchromacity and nuclear pleomorphism. ${ }^{5}$

The most appropriate management of these tumours is a subject of debate. With only 6 cases reported and a lack of adequate follow-up data on these cases, optimum treatment is far from settled. In only two cases was a complete removal of tumour possible. ${ }^{3,5}$ No follow-up is given by Cuneo and Rand, and the patient reported by Levy et al died from complications one month following surgery. In all other cases, including ours, the tumour was too extensive to allow complete resection (Table 1).

The most aggressive surgical approach was taken by Levy et $\mathrm{al}^{5}$ in their second case. They performed a subtemporal, followed two weeks later by a suboccipital, approach for resection of as much tumour as possible from middle and posterior fossa. This was followed by a course of radiotherapy. They advocate this approach as opposed to radiotherapy as the sole mode of treatment.

Hedeman et $\mathrm{al}^{4}$ also report good results in their first patient when a course of radiotherapy was given subsequent to subtotal tumour excision, via subtemporal approach. Their patient was alive at 18 month follow-up, which represents the longest follow-up of the six cases.

A more conservative approach was taken by Hedeman et $\mathrm{al}^{4}$ with their second patient. Following transnasal biopsy this

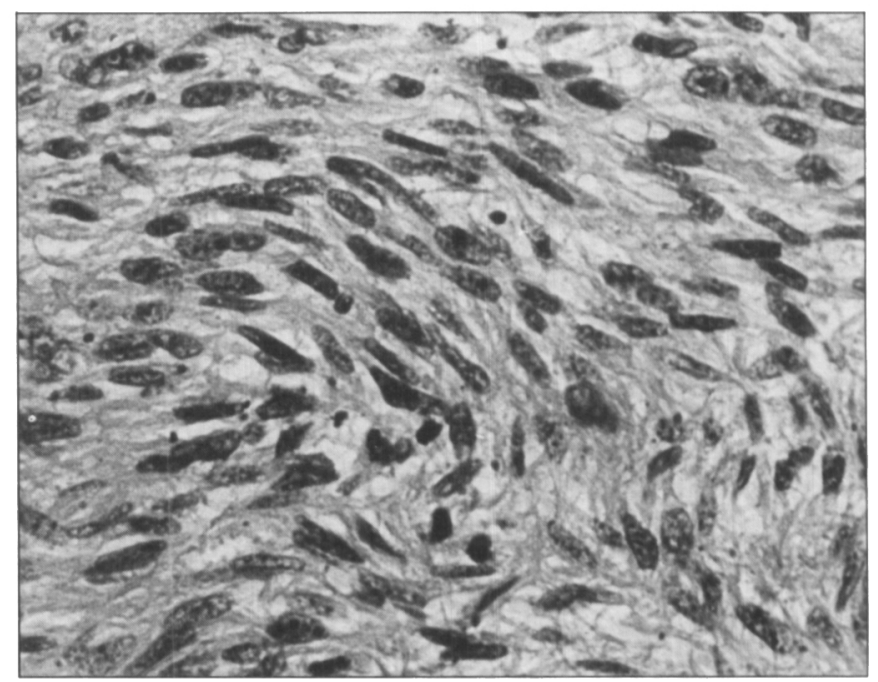

Figure 3: Microscopy showing spindle-celled tumour with malignamt characteristics. Note hyperchromaticity and nuclear pleomorphism: $x$ 1000 . 
THE CANADIAN JOURNAL OF NEUROLOGICAL SCIENCES

Table I: Primary malignant tumours of the trigeminal nerve

\begin{tabular}{lcccccc}
\hline \hline & Age & Sex & Surgery & Radiotherapy & Follow-up \\
\hline Cuneo and Rand $1952^{3}$ & 52 & M & $\begin{array}{l}\text { Subtemporal } \\
\text { subtotal removal }\end{array}$ & None & Not reported \\
\hline Hedeman et al $1978^{4}$ & 50 & M & Transnasal biopsy & 5400 rads & $\begin{array}{l}\text { Completely asymptomatic } \\
\text { at } 14 \text { months }\end{array}$ \\
\cline { 2 - 6 } & 53 & M & $\begin{array}{l}\text { Subtemporal } \\
\text { subtotal removal }\end{array}$ & 5175 rads & $\begin{array}{l}\text { Alive } 18 \text { months post-radiation } \\
\text { treatment }\end{array}$ \\
\hline Levy et al $1983^{5}$ & 61 & M & $\begin{array}{l}\text { Subtemporal plus } \\
\text { subocipital } \\
\text { subtotal removal }\end{array}$ & 6000 rads & $\begin{array}{l}10 \text { month follow-up; } \\
\text { satisfactory }\end{array}$ \\
\cline { 2 - 6 } & 67 & F & $\begin{array}{l}\text { Subtemporal } \\
\text { complete removal }\end{array}$ & None & $\begin{array}{l}\text { Died during post-operative } \\
\text { period of probable sepsis }\end{array}$ \\
\hline Maroun et al (present case) & 49 & F & Transnasal biopsy & 6000 rads & Alive with cranial nerve deficit \\
\hline
\end{tabular}

patient was treated with a course of radiotherapy. Follow-up at 14 months showed this patient to be asymptomatic.

Because of the tumour extension in our case we decided to take a similar course. However, her tumour seemed particularly aggressive as judged by the rapidity of tumour growth, and its continued growth, despite radiotherapy, as judged by the development of new symptoms. Wander and Das Gupta $(1977)^{13}$ state that neurofibrosarcomas are the most highly malignant of all sarcomas. The clinical course in our patient would support this statement.

Based on the six cases a reasonable treatment approach would be to aim for complete surgical removal, if the tumour is

\section{REFERENCES}

1. Glasauer FE, Tandon PN. Trigeminal neuroma in adolescents. J Nerol Neurosurg Psych 1969; 32: 562-568.

2. Mello LR, Tanzer A. Some aspects of trigeminal neurinomas. Neuroradiology 1972; 4: 215-221.

3. Cuneo HM, Rand DW. Tumours of the gasserian ganglion. Tumour of the left gasserian ganglion associated with enlargement of the mandibular nerve. A review of the literature and case report. J Neurosurg 1952; 9: 423-431.

4. Hedeman LS, Lewinsky BS, Lochridge GK. Trevor R. Primary malignant schwannoma of the gasserian ganglion: Report of two cases. J Neurosurg 1978; 48: 279-283.

5. Levy WJ, Ansbacher L, Nutkiewiez A. Fratkin J. Primary malignant nerve sheath tumour of the gasserian ganglion: A report of two cases. Neurosurgery 1983: 13: 573-576.

6. Ghosh BC. Ghosh L. Huvos AG, Fortner JG. Malignant schwannoma A clinicopathological study. Cancer 1973: 1: 184-190.

7. D'Agostino AN, Soule EH, Miller RN. Primary malignant neoplasms of nerves (malignant neurilemomas) in patients without small and well localized. This should be followed by radiation therapy (which was shown to totally control the first patient reported by Hedeman et $\mathrm{al}^{4}$ when used as the sole mode of therapy). Post-operative growth of malignant tumours of the acoustic nerve have also been shown to be controlled by radiotherapy. ${ }^{14}$

Where total surgical removal is not possible, a one or twostage procedure for tumour debulking, followed by radiotherapy may be beneficial (as was shown by the first case, Levy et $\mathrm{al}^{5}$ ). However, more experience will be required before an aggressive approach, with its inherent risks, can be advocated.

manifestations of multiple neurofibromatosis (Von Recklinghausen's disease). Cancer 1963; 16: 1003-1014.

8. Nambisan RN, Rao U, Moore R, Karakousis CP. Malignant soft tissue tumours of nerve sheath origin. J Surg Oncol 1984; 25: 268-272.

9. Bergstrom $R$. Changes in peripheral nerve tissue after irradiation with high energy protons. Acta Radiol 1962; 58: 301-312.

10. Meadows AT, D'Angio GJ, Mike $V$ et al. Patterns of second malignant neoplasms in children. Cancer 1977; 40: 1903-1911.

11. Ducatman BS, Scheithauer BW. Postirradiation neurofibrosarcoma. Cancer 1983; 51: 1028-1033.

12. Brasfield RD, Das Gupta TK. Von Recklinghausen's disease: A clinicopathological study. Ann Surg 1972; 175: 86-103.

13. Wander JV, Das Gupta TK. Neurofibromatosis. Curr Prob Surg 1977: 14: 36-45.

14. Newman H, Sheline GE. Radiation therapy of tumours of the eighth nerve sheath. AJR 1974; 120: 562-567. 